\title{
In situ detection of monovalent copper in aerosols by photoemission
}

\author{
M. Ammann ', R. Haucrt ${ }^{2}$, and H. Burtscher' \\ 1 Swiss Federal Institute of Technology, Solid State Physies, ETII I Iönggerberg, CH-8093 Zürich, Switzerland \\ 2 Swiss Federal Laboratories for Materials Testing and Research, C11-8600 Dübendorf, Switzerland
}

Received November 6, 1991

Summary. In situ information on nanoparticle surface chemistry and modes of particle growth is obtained in gas suspension by the technicue of photoelectric charging of particles $(\mathrm{PCl})$ which depends on the surface chemical compositon as well as the electronic structure of the particles via the spectral dependence of the photoelectric yickl. With $\mathrm{CuCl}$ particles, pholoclectric charging is about 100 times more efficient compared to other divalent transition metal compounds. Therefore, particles containing monovalent $\mathrm{Cu}$ caln be detected with extremely high sensitivity of below $10 \mathrm{ng} / \mathrm{m}^{3}$. In atmospheric acrosols cmitted from volcanoes, the relation of solid state oxidation/reduction in $\mathrm{Fe}_{1-} \mathrm{Cu}_{x} \mathrm{Cl}_{2}$ resulting in monovalent $\mathrm{Cu}$ for $\mathrm{x}<0.4$ is important. As an cxample of the PCP technique this relation is monitored in laboralory generated acrosols. The nanoparticles are also precipitated onto a substrate where their surface chemical composition is analyzed by XPS which is important for the interpretition of the results obtained by photoclectric charging.

\section{Introduction}

Natural and anthropogenic sources emit about 30000 tons of particulate copper per year into the almosphere [1]. About $70 \%$ are emilted as ultrafine acrosol particles in volcanic gases [2]. Ficld studies at different volcanoes have shown the fractionation of magmatic copper in volcanic gases [3] and its importance for volcano monitoring purposes [4]. Copper is emitted as a monovalent copper chloride and is cmbedded with an iron oxide in alkali chloride crystals in the nanometer size range. In long term exposure to the atmosphere of a volcanic plume containing $\mathrm{SO}_{2}$ and $\mathrm{H}_{2} \mathrm{SO}_{4}$, the conversion of the chlorides into sulphates must be taken into account to understand the behaviour of copper containing acrosols in the atmosphere.

Ultrafine acrosol sampling in the field as well as in the laboratory requires extremely long sampling limes to get enough material for standard chemical analysis. In addition sophisticited filters must be designed for the fillation of very small particles. Very often further chemical reactions on the fillers cannot be excluded. Therefore in situ measurement

Offprint requests to: H. Burtscher lechnicues are highly needed, offering the additional advantage of online analysis, which is not only fruitful in acrosol measurements in an atmospheric environment but also in controlling of nanoparticle processing in the ficld of material technology.

Up to now pholoclectric charging of particles (PCP), also known as acrosol photoemission is the only in situ acrosol analysis technicute beeing capable of both sensing the surface and the internal chemical structure of ultrafine particles [5]. The analylical potential of acrosol photoemission has previously been used to investigate oxygen adsorption on clean metal particles [6], coating of soot particles with organies [7] and the detection of heavy metal acrosols [8].

In this work, PCP is applied to some simple inorganic compounds of alkali and transition metal elements in vicw of applications with complex chemical structures of acrosol particles. Special emphasis will be on the delection of monovalent copper compounds. This will be applied to the monitoring of an relation of oxidation/reduction between $\mathrm{Fe}(\mathrm{II}) / \mathrm{Cu}(\mathrm{II})$ and $\mathrm{Fe}(\mathrm{III}) / \mathrm{Cu}(\mathrm{I})$ in small particles.

\section{Aerosol generation}

In order to produce aerosol parlicles of known chemical composition two common acrosol generation techniques hatve been applied [9]: 1) the gas evaporation technique in a lube furnace for volatile compounds beeing stable as gaseous molecules at elevated temperatures and 2) alomization in a solution nebulizer for waler soluble malterials.

\subsection{Tube finnace}

$A$ carrier gas (filtered air of $\mathrm{N}_{2}$ ) is led over a sample of the desired malerial willin a ceramic lube furnace. The temperature in the furnace can be adjusted between 100 and $1000^{\circ} \mathrm{C}$. According to the temperature and the vapour pressure of the material, particles are formed in the carrier gats after the sample by homogeneous nucleation and condensation leading to a lognormal size distribution between 2 and $20 \mathrm{~nm}$ in radius. For this study acrosol particles of $\mathrm{NaCl}, \mathrm{KCl}, \mathrm{MgCl}_{2}, \mathrm{CuCl}, \mathrm{ZnCl}, \mathrm{FeCl}_{2}, \mathrm{PbBr}_{2}$ have been produced by this method. To avoid particle agglomeration the temperature was adjusted to give concentrations smaller than $10^{6}$ particles per $\mathrm{cm}^{3}$. 


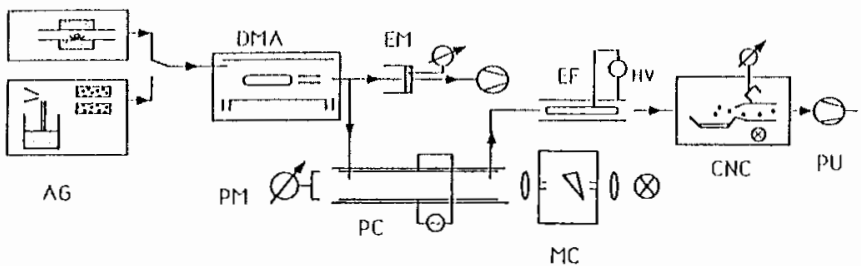

Fig. 1. Experimental setup for measurement of the photoelectric yicld as function of particle size and photon energy. $A G \Lambda$ erosol gencrator; $D M A$ Difterential mobility analyzer; $E M$ Electrometer; PM Photodetector; $P C$ Photocmission chamber; $M C$ Prism monochromator; EF Electrostatic precipitator; CNC Condensation Nucleus Counter; PU Pump

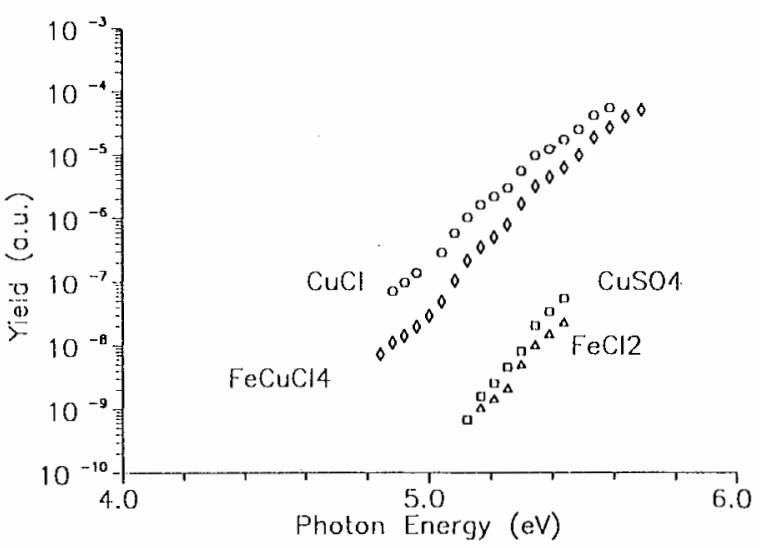

Fig. 2. Photodectric yield (emilted electrons per incident photon) as finction of the photon energy for acrosols consisting of $\mathrm{CuCl}$ $\mathrm{fichCl}_{4}, \mathrm{CuSO}_{4}, \mathrm{l}_{\mathrm{C}} \mathrm{Cl}_{2}$. Eequivalent mobility radii of the particles are $9.5 \mathrm{~nm}, 17 \mathrm{~nm}, 21 \mathrm{~mm}, 21 \mathrm{~nm}$, respectively

\subsection{Solution nebulizer}

A solution containing a chloride or sulphate as solute is dispersed in a carricr gas into small droplets of some microns in diameler by a simple spray technicpuc. In a diffusion diryer filled with silicagel the water evaporales feaving solid particles of the solute with radii between 5 and $50 \mathrm{~nm}$. By this technique acrosols of $\mathrm{Na}_{2} \mathrm{SO}_{4}, \mathrm{~K}_{2} \mathrm{SO}_{4}, \mathrm{CuSO}_{4}, \mathrm{CuCl}_{2}$; $\mathrm{FeSO}_{4}, \mathrm{MgSO}_{4}, \mathrm{ZnSO}_{4}$ have been generaled. Again the amount of solute is low enough to produce not more than $10^{6}$ parlicles per $\mathrm{cm}^{3}$.

\section{Aerosol analysis}

\subsection{Photoelectric charging of particles (PCP)}

In PCP particles suspended in the carrier gas are irradiated with UV light of energy close to the photoelectric threshold. If the energy of the light is higher than the photoelectric threshold, electrons may be emitted from the particles, thus neutralizing particles with one initial negalive charge or charging initially neutral particles positively. The photoelectric yield for light of energy $\mathrm{E}$ is defined as

$Y=i_{\mathrm{e}} / 4 \pi R^{2} \mathrm{j}(\mathrm{E})$

where $i_{\mathrm{c}}$ denotes the flux of emilted electrons per second, $4 \pi$ $\mathrm{R}^{2}$ the emitling surface arcat assuming a spherical particle of radius $R$, and $j(E)$ the photon flux density at energy $E$. Within the light energy range of 4 to $10 \mathrm{eV}$ and for particle radii below $50 \mathrm{~nm}$ the yield of photoclectrons is mainly deter-

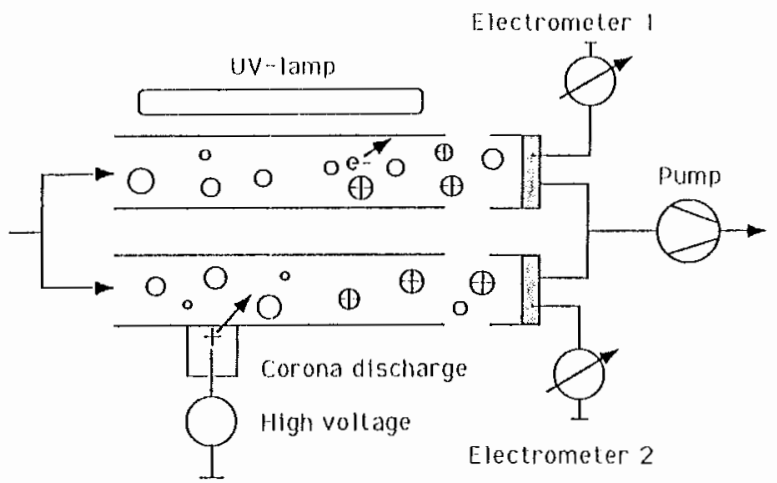

Fig. 3. Schemalic diagram of the PCP probe. The pholoclectric activily is determined by the quotient of the signals from electrometers 1 and 2. The flow rate is $66.7 \mathrm{~cm}^{3} / \mathrm{s}$ in each channel

mined by the escape probability of the excited electrons, justifying the use of $4 \pi \mathrm{R}^{2}$ in the definition of the yield. The apparalus shown in Fig. 1 has been used to measure the photoelectric yicld as function of the photon energy and the particle size. The differential mobility analyzer (DMA) [9] selects negatively charged particles of one elect rical mobility from the polydisperse size spectrum produced by the acrosol generators described above. The so-called equivalent mobility radius $R$ can be calculated from the electrical mobility [9]. The tolal gas flow rate of $66.7 \mathrm{~cm}^{3} / \mathrm{s}$ through the apparatus is provided by a pump. An electromeler measares the concentration of particles leaving the DMA. The intensity of the parallel UV light beam from a high pressure $\mathrm{Xe} / \mathrm{Hg}$ lamp followed by a prism nonochromator is measured with a photometer at the end of the photocmission chamber. There part of the initially negatively charged particles are neutralized by emission of photoclectrons. The highly mobile emitted electrons are removed by an alternating electric field in the photoemission chamber to prevent them from attachment to other particles. After electrostatic precipitation of the remaining negative particles in a cylindrical condensor, the neutral particles are counted with a condensation nucleus counter (CNC, TSI Model 3025) [9]. As long as the fraction of neutralized particles remains small (usually up to 1\%), the signal of the CNC ecpuals the amount of photoclectrons emitled in the photoemission chamber when neglecting particle losses to the wall within the apparalus. The photoelectric yield can be determined by dividing the $\mathrm{CNC}$ signal through the light intensily, the particle concentration and $4 \pi R^{2}$. As an example, Fig. 2 shows the photoclectric yietd of acrosols of some transition metal compounds as function of the incident light energy.

Much higher sensilivity at a fixed light energy is obtained with an even simpler apparatus. Designed as a compact probe, it can be used in the laboratory as well as in the lield [10] (lig. 3). The increase in sensitivily is achieved by giving up the size selectivity and by using a low pressure mereury lamp with an intense line at $6.7 \mathrm{cV}$ without a monochromator. In this case initially ncutal particles are charged in the photocmission chamber due to electron emission upon UV irradiation. To obtain a measure for the surface area $4 \pi$ $\mathrm{R}^{2}$ of the particles, the flow of neutral particles is split into two parts, one passing the photocmission chamber, the other going through an ion atlachment unit, where positive ions are produced by an electric corona discharge. For spherical 
Table 1. Photodectric activity e (mcasured at $6.7 \mathrm{cV}$ ) for aerosols of various inorganic salts

\begin{tabular}{|c|c|c|}
\hline Compound & $\varepsilon$ & Exp. \\
\hline$\left(\mathrm{NHI}_{4}\right)_{2} \mathrm{SO}_{4}$ & 0 & $s$ \\
\hline $\mathrm{NaCl}$ & 0 & $\mathrm{l}, \mathrm{s}$ \\
\hline $\mathrm{Nat}_{2} \mathrm{SO}_{4}$ & 0 & s \\
\hline $\mathrm{MgCl}_{2}$ & 0 & s \\
\hline $\mathrm{KCl}$ & 0 & li,s \\
\hline $\mathrm{K}_{2} \mathrm{SO}_{4}$ & 0 & s \\
\hline $\mathrm{CaCl}_{2}$ & 0 & $s$ \\
\hline $\mathrm{FeCl}_{2}$ & 0.05 & $l, s$ \\
\hline $\mathrm{FeSO}_{4}$ & 0.02 & $\mathrm{~s}$ \\
\hline $\mathrm{CuCl}$ & 0.9 & 1 \\
\hline $\mathrm{CuCl}_{2}$ & 0.02 & $\mathrm{~s}$ \\
\hline $\mathrm{CuSO}_{4}$ & 0.02 & s \\
\hline $\mathrm{ZnCl} \mathrm{nCl}_{2}$ & 0 & $\lceil, \mathrm{~s}$ \\
\hline $\mathrm{ZnSO}_{4}$ & 0 & s \\
\hline $\mathrm{SnCl}_{2}$ & 0.04 & $s$ \\
\hline $\mathrm{PbBH}_{2}$ & 0.02 & $\Gamma$ \\
\hline
\end{tabular}

' $\rho$ ' and 's' denote particle generation with tube furnace and solution nebulizer, respectively

particles with radii below $100 \mathrm{~nm}$ the charge acquired in the latter is proportional to the surface area $4 \pi \mathrm{R}^{2}$ but is independent of the material. Apter removal of remaining ions in the gas by a weak electric lick, the flux of charged particles is measured with electrometers. The ratio of the charges in the two channels is called photoelectric activity s. As the photoelectric charge depends on the light intensity of the lamp, the intensity is monitored in all experiments to ofler the possiblity of new calibration in case of changes. This ensures reproducible operating conditions. Thus, dividing the pholoelectric charges by the surface area gives photoclectric activity s as a normalized quantity which is proportional to the photoclectric yield at $6.7 \mathrm{cV}$. On the one hand, $a$ is dependent on the shape of the photoelectric yield curve which is more or less a material constant. On the other hand, 8 depends on the photoclectric threshold, which is at function of the electronic structure of the material and of the surface of the acrosol particles as well (geometry, adsorbed surlace layers). Assuming that in most transition melal compounds the density of states close to the vacuum level is largely constant so that light absorption in the range of 4 to $10 \mathrm{cV}$ is not a strong function of the photon energy, the yickd curve for a material (sec for example fig. 2) shifts parallel along the energy axis, when the threshold is shifted by changes on the particle surface.

With the described experimental setup, the values of $:$ range from $10^{-4}$ up 1010 . Limitations are imposed by small ion allachment coeflicients for very small particles, the sensilivity of the electrometer $\left(10^{-15} \mathrm{~A}\right)$ and multiple photocmission charging effects for particles with very high photoclectric activity.

\subsection{X-ray photoelectron spectroscopy (XPS-ESCA)}

In order to get more complete chemical information on the surface of the particles, acrosol samples are further investigaled by XPS.

Sampling is achieved as follows: neutral particles are charged by ion attachment and then precipitated electrostatically on a HOPG surface (highly oriented pyrolytic graphite). A monolayer of particles (enough for analysis) on the substrate requires sampling times of the order of $1 \mathrm{~h}$ for particles $10 \mathrm{~mm}$ in radius and $10^{6} \mathrm{~cm}^{-3}$ concentration. To prevent the samples from oxidation they are kept in a noble gas environment until transfer into the XPS apparatus.

In XPS the surface under investigation is irradiated by monoenergetic $\mathrm{X}$-rays $(\mathrm{Mg}-\mathrm{K} \alpha$ radiation at $\mathrm{hv}=$ $1253.6 \mathrm{eV})$. The energy spectrum of the emitted photoclectrons provides an image of the binding energies of the core electrons from the elements present at the surface. The small deviations of the peak positions namely the chemical shifts, reveal the valence state or the chemical environment of the different elements involved. The analyzed depth is determined by the inclastic mean free path of the excited clectrons and ranges from 1 to $3 \mathrm{~nm}$.

XPS measurements were carried out on a Perkin Elmer PHI 5400 ESCA system. The electron energy analyzer was operated at a constant pass energy of $35.36 \mathrm{eV}$, the total encrgy resolution being $0.89 \mathrm{cV}\left(\mathrm{Ag} 3 \mathrm{~d}_{3 / 2}\right)$, analyzing an arca of $1.1 \mathrm{~mm}$ in diameter. The binding energy scale was calibrated for the $A u 4 \int_{7 / 2}$ signal at $83.8+0.1 \mathrm{cV}$. The base pressure was $4 \times 10^{-10}$ mbar. Further details concerning surface analysis by XPS-ESCA can be found in the book of Briggs and Seah [11].

\section{Results and discussion}

\subsection{Photoelectric activity of $\mathrm{CuCl}$}

As stated above the photoelectric activity : provides a general parameter sensing the surface of the particles as well ats the chemical composition. To get an overall picture of the possible analytical capability of this method : was measured for a number of alkali, alkali earth and transition metal compounds as acrosol particles suspended in air. The results are summarized in Table 1 . As the ionization potential of alkali chlorides is higher than $8 \mathrm{eV}$ [12], the pholoelectric activity of $\mathrm{KCl}, \mathrm{NaCl}, \mathrm{K}_{2} \mathrm{SO}_{4}, \mathrm{Na}_{2} \mathrm{SO}_{4}$ measured at $6.7 \mathrm{cV}$ is zero. For the same reason 8 is zero for $\mathrm{MgCl}_{2}$ and $\mathrm{CaCl}_{2}$ as well as for $\mathrm{ZnCl}_{2}$, which has an ionization energy of $12.9 \mathrm{eV}[13]$. : values of the order of $10^{-2}$ are found for the group IV dihalides of $\mathrm{Pb}$ and $\mathrm{Sn}$. The same order of magnitude has been obtained from the transition metal dihalides and sulphates of $\mathrm{Cu}$ and $\mathrm{Fe}$, whereas the photoelectric activity of the monovalent $\mathrm{CuCl}$ is by orders of magnitudes higher which may also be infered from Fig. 2. This ligure shows that the photoclectric threshold (i.e. the onset of photoemission) for the investigated iron and copper compounds lies below $5 \mathrm{eV}$. This relatively low threshold (a clean $\mathrm{CuCl}$ surface has a photoclectric threshold of $6.8 \mathrm{cV}$ [14]) is due to the formation of an oxide layer on the surface of the particles after exposure to ambient ait. A similar behaviour of the photoclectric threshold after oxygen exposure is also observed in Ni metal particles [15] when the oxide forms on the surface. Figure 4 shows the XPS spectrum of $\mathrm{CuCl}$ particles with the fourfold splitted 2 p line indicating the presence of $\mathrm{Cu}(\mathrm{II})$ ions on the particle surface (monovalent $\mathrm{Cu}(\mathrm{I})$ reveals only a twofold splitted $2 \mathrm{p}$ line). The latrge difference in photoelectric activity $:$ between the monovalent and the divalent copper compounds is mainly due to the difference in the photoelectric yield. This effect can be used to deted monovalent copper ions among other compounds within small acrosol particles with high sensitivity. The detection limit of the electrometers used in 


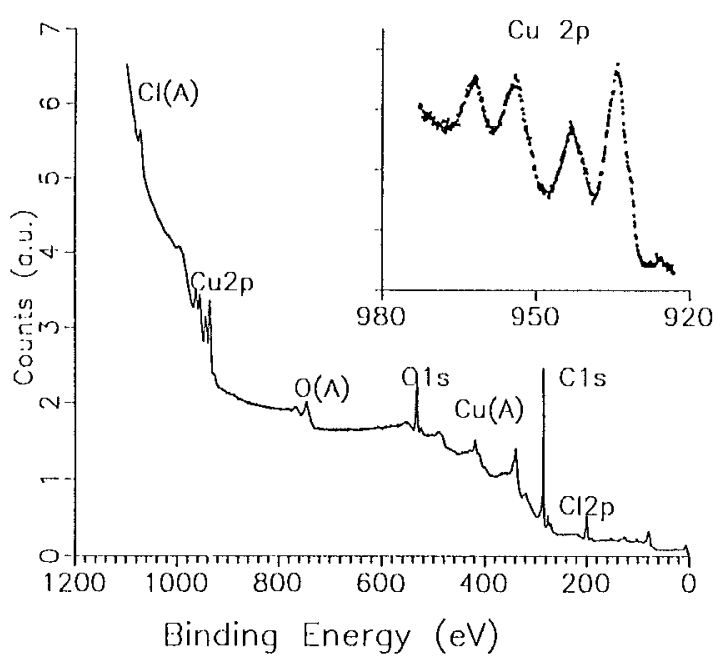

lïg. 4. XPS-spectrum of CuCl acrosols precipitaled on HOPG substrate (als deposited). A denole lines from Auger transitions. Indent: Cu $2 p$ line with characteristical satellite structure of Cu(II)

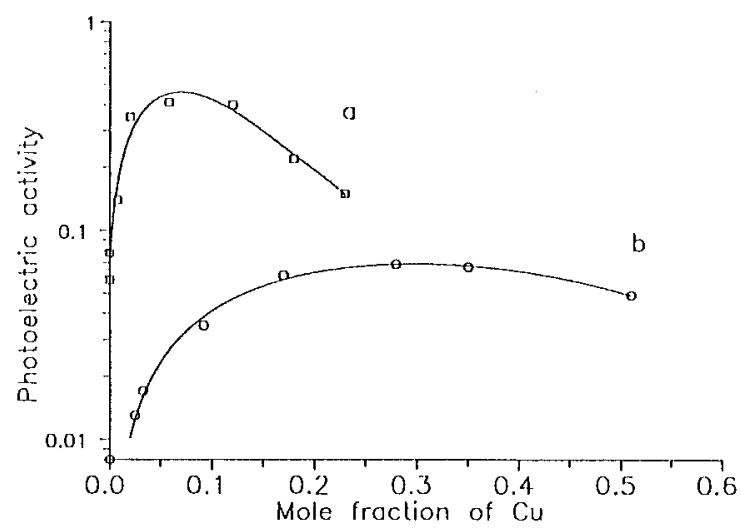

Fig. 5. Photoclectric activity s as function of Cu mole fraction in mixed sodium-iron chloride (a) and sulphate (b) atcrosols. lie/ $/ \mathrm{Na}=$ 0.099 in $(a)$ and $\mathrm{Fe} / \mathrm{Nal}=0.18$ in $($ b)

the instrument (ligi. 3) is below $10^{-15} \mathrm{~A}$. When working with how rales of $66.7 \mathrm{~cm}^{3} / \mathrm{s}$ this corresponds 10 a charge concentration of $10^{2}$ charges per $\mathrm{cm}^{3}$. The ion allachment efficiencies are of the order of $20 \%$ for particles with raldii of $10 \mathrm{~nm}[9]$, : becing close to $1 . \wedge \mathrm{CuCl}$ particle concentration of less than $10^{3} \mathrm{~cm}^{-3}$ can produce still measurable currents in both electrometers. The sensitivity for an in situ measurement of $\mathrm{CuCl}$ as acrosols is thus of the order of $10 \mathrm{ng} / \mathrm{m}^{3}$ corresponding 10 a mass flux of $0.04 \mathrm{ng}$ per minute.

The relationship between the $\mathrm{CuCl}$ mass concentration of a purc $\mathrm{CuCl}$ acrosol and the photoemission charging rate has not been investigated systematically, but in all the experiments the photodectric activity of CuCl for different sizes and concentrations was the same (deviations have never been larger than $5 \%$ ). 'Thus the photoemission charging rate increases lincarly with increasing particle surface areal.

PCP may be used when monovalent copper must be detected among other divalent transition metal compounds in similar amounts. In mixlures will materials wilh very high photoclectric thresholds, for example when $\mathrm{CuCl}$ is cmbedded in NaCl crystals, part of the photoelectrons mily be absorbed by the $\mathrm{NaCl}$, and probably the pholoelectric threshold of the particles is a function of the relative $\mathrm{CuCl}$ content, thus giving rise to an underestimation of the $\mathrm{CuCl}$ content.

The high photoclectric yield of $\mathrm{CuCl}$ is in agreement with the work of Krolikowski [16], where normalized yield data are available lor bulk $\mathrm{Cul}$, and with the yield of CuBr reported by Lin et al. [17]. Goldmann [14] discussed the electronic structure of the tetrahed rally coordinated cuprous halides. The key feature seems to be the partial ligand $p$ admixture to the copper $3 d$ bands. The partial $p$ and $d$ densities of states neat the top of the valence band, from where electrons in UV photocmission are excited, could be determined only with limited accuracy in the work of Goldmann [18].

The only PCP measurement of a monovalent copper compound is reported by Niessner et al. [8], where $\mathrm{Cu}_{2} \mathrm{O}$ particles were analyzed with an aerosol photoemission sensor array with different UV irradiation wavelengths $(185$, $214,229,254 \mathrm{~nm}$ ). The $\mathrm{Cu}_{2} \mathrm{O}$ parlicles could be charged photoclectrically al all light energies, whereas none of the energies was high enough to ionize particles of $\mathrm{C} n \mathrm{O}$, in agreement with our findings of the difference in photoclectric activity between the monovalent and the divalent copper compound.

\subsection{Copper valence in mixed iron copper chloride aerosols}

In experiments with different salt mixtures from the solution nebulizer an enhancement of photoclectric aclivity \& has been observed when divalent iron and copper salts are used together. Referring to the measurements summarized in Table 1 this enhancement is supposed to be due to a reduction of the divalent copper ions. In the experiment summarized in Fig. 5 the intial solution in the solution nebulizer contained $91 \% \mathrm{Na}^{*}$ and $9 \% \mathrm{Fe}^{2+}$ as cations and $\mathrm{Cl}^{-}$as anion (Fig. 5 a) before different amounts of $\mathrm{CuCl}_{2}$ have been added. In the same way sulphate solutions have been prepared starting with $85 \% \mathrm{Na}^{+}$and $15 \% \mathrm{Fe}^{2+}$ and adding $\mathrm{CuSO}_{4}$ (lig. 5b). The photoclectric activity of of the resulting particles is plotted against the relative fraction of Cu ions in the acrosols. In both cases a distinet maximum is observed when the Cu fraction is in the order of the Fe(II) fraction, the height of the maximum indicaling almost complete reduction of $\mathrm{Cu}(\mathrm{II}) \mathrm{lo} \mathrm{Cu}(\mathrm{I})$.

l'o get more defined conditions, the experiment has been repeated without using a sodium chloride matrix and by working with the experimental setup shown in Fig. 1. As discussed in the previous section, 8 is related to the photoelectric yicld at $6.7 \mathrm{cV}$. Figure 6 shows the relative photoelectric yicld at $5.4 \mathrm{eV}$ of $\mathrm{Cu}_{x} \mathrm{Fe}_{1-x} \mathrm{Cl}_{2}$ particles with radii of $17 \mathrm{~mm}$ measured as function of $x$ in liflered air as carrice gas. Again a marked maximum in the yield is measured for $x=0.4$. The yicld for $x=1$ lies below the detection fimit of the apparalus which is identical with the lower limit of the scale in lig. 6. In order to get evidence of the supposed reduction of the divalent copper due to the presence of divalent iron, samples of acrosols with $x=0, x=0.3, x=$ 0.9 and $x=1$ have been analysed by XPS. The relevant $\mathrm{Cu}_{21}$ and $\mathrm{Fe}_{2 \mathrm{p}}$ lines of the XPS spectrum are presented in rig. 7 a and b, respectively. Up to Cu fations corresponding to the maximum of fiig. 6 the only twofold splitted line (Fig. 7 a, $\mathrm{x}=0.3$ ) indicales complete reduction to Cu(l) whereats lor larger fractions (Fig. $7 \mathrm{a}, \mathrm{x}=0.9$ and $\mathrm{x}=1$ ) the fourfold splitted part of the line increases showing the partial oxida- 


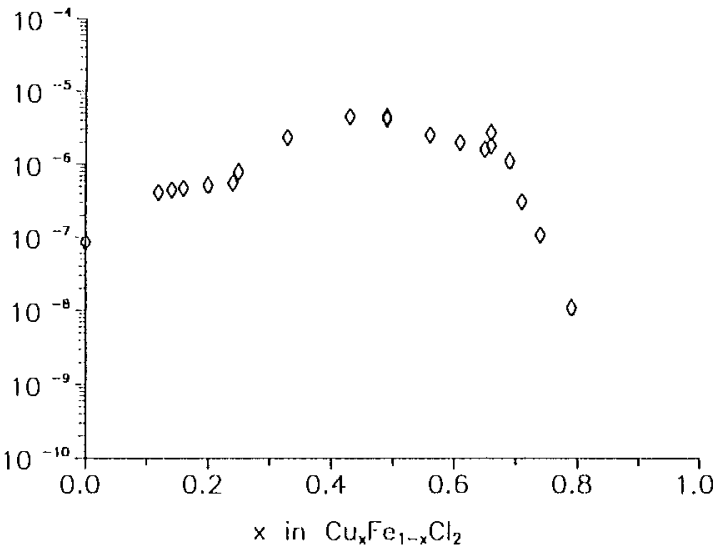

lijg. 6. Relative photoclectric yield at $5.39 \mathrm{eV}$ as function of the $\mathrm{Cu}$ fraction $\mathrm{x}$ in $\mathrm{Cu}_{\mathbf{x}} \mathrm{l}^{\mathrm{l}} \mathrm{C}_{1-\mathrm{x}_{2}} \mathrm{Cl}_{2}$ particles suspended in air

tion, according to the relative amount of $\mathrm{Fe}(\mathrm{II})$ in the particles. In the same lime the $F_{e_{2 p}}$ line shifts from the Fe(II) position (710.4 cV) for $x=0$ to the Fe(III) position $(711.2 \mathrm{cV})$ for complete oxidation at $x=0.9$. Clarly partial oxidation can be seen for $x=0.3$. Thus the PCP measurement contains already the complete information on the distribution of $\mathrm{Cu}(\mathrm{I})$ and $\mathrm{Cu}(\mathrm{II})$ in the aerosol particles.

The standard reduction potentials [West et al. 1984] do nol allow such a redox process to occur in acpucous solutions. A solid state reaction within the acrosol particles is assumed similar to that described by D'Husser et al. 119] for bulk copper ferrites. The maximum in Fig. 6 near $x=0.4$ indicales reduction of $\mathrm{Cu}(\mathrm{Il})$ by two thirds of the Fe(II) ions present in the particles, pointing probably to different coordination sites of the ions in analogy to the copper ferrites.

Being sensitive to the sample surface only, XPS shows that Cu(I) is not oxidized on the particle surlace by exposure to ambient air as it occurs in pure $\mathrm{CuCl}$ particles (Fig. 4). Thus the reduction oxidation equilibrium between iron and copper ions has an important implication for the measurement of altmospheric acrosol particles in the vicinity of voleanoes: in the volcanic gats copper is condensing as a monovalent compound which is not oxidized in ambient air due to the presence of iron oxides within the particles.

\section{Conclusions}

Photoclectric charging of particles (PCP), an extremely sensitive in situ acrosol analytic tool, hats been applicel to alkali and transition melal chlorides and sulphates. The most striking feature is the very high photoclectric yicld of particles consisting of monovalent copper compounds, compared to the divalent compounds of copper and iron. Will pure CuCl particles, XPS on precipitated particles reveals the oxidized surlace layer lowering the photoctectric threshold. This lowering of the photoclectric threshold combined with the sharp increase of the intrinsic photoctectric yield of $\mathrm{CuCl}$ explains the high photoclectric aclivity, which is proportional to the yicld at $6.7 \mathrm{cV}$. PCP therefore allows the in situ detection of fine $\mathrm{CuCl}$ acrosol particles in the nanometer size range in conecntrations below $10 \mathrm{ngm}^{-3}$. As an application a solid state redox reaction of $\mathrm{Cu}(\mathrm{II}) / \mathrm{le}(\mathrm{II})$ has been monitored in $\mathrm{F}_{1-{ }_{x}} \mathrm{Cu}_{x} \mathrm{Cl}_{2}$ parlicles as well as in alkali salt particles containing traces of lie and
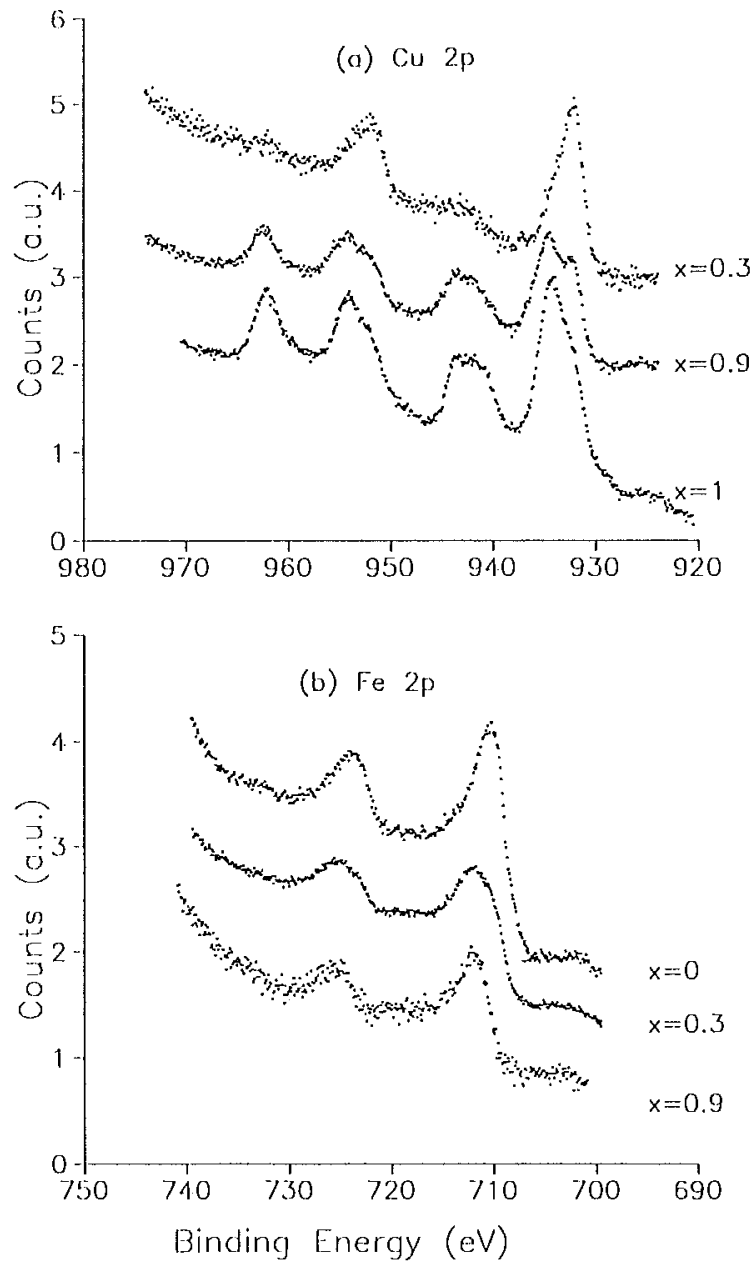

liig. 7. Cu $2 p$ (a) and lic $2 p$ (b) lines from XPS spectrat as deposited of samples of $\mathrm{Cu}_{\mathrm{x}} \mathrm{l}_{\mathrm{C}} \mathrm{C}_{1} \mathrm{Cl}_{2}$ particles for various $\mathrm{Cu}$ fractions $\mathrm{x}$

Cu ions. For $x<0.4$, Cu is only present as Cu(I), even at the surfice of the particles, as shown by the Xl'S spectrit.

This redox equilibrium preserves the monovalent copper ions in the acrosol particles from oxidation in ambient air under the condition that enough iron is present. PCP is now successfully applied in field measurements at a volcano for monitoring the particulate copper emissions in the voleanic gils.

In conclusion, quantitative determinalion of copper valence in complex nanoparticle systems is not out of sight. Beside its relevance in volcanic acrosols, possible applicaltions in the lield of superconducting materials should be discussed, where the valence of copper plays a crucial role.

deknowledgrament. We are gratclul to L. Scherrer for his technical support and the development of the PCP probe. We thank Prof. 11. C. Siegmann for bis contribution to this project and the many fruilful discussions.

\section{References}

1. Nriagu JO, Pacyna JM (1988) Nature 333:134-139

2. Le Cloarec M-1: Marty B (1991) Terra Nova 3:17-- 27

3. Pennisi G, Le Cloarec M-F, Limbert G, Le Roulley IC (1988) larth Planet Sci Lell 88:284-288

4. Ammam M, Hatuer R, Burtscher II, Siegmann IIC (192)1) submilled to J Geophys Res 
5. Burtscher H, Scherrer L, Siegmann HC, Schmidt-OU $A$, Federer B (1982) J Appl Phys 53:3787-3791

6. Müller U, Schmidt-Otl $\wedge$, Burtscher II (1987) Phys Rev Lell $58: 1684-1686$

7. Burtscher H, Schmidt-Ott $\wedge$ (1986) J Acrosol Sci 17:669_- 703

8. Niessner R, Hemmerich B, Panne U (1989) Fresenius Z Anal Chem '335:728-737

9. Hidy GM (1984) Acrosols, An lndustrial and Environmental Science. Academic Press, Orlando

10. Ammann M, Burtscher II (1990) Bull Volcanol 52:577- 583

11. Briggs D, Scah MP (1990) Practical surface analysis. Wilcy, New York

12. Weast RC, Astle MJ, Beyer WII (1984) Handbook of chemistry and physics. CRC P'ress, Boca Raton
13. Bailar JC (1973) Comprehensive inorganic chemistry. Pergamon Press, Oxford

14. Goldmamn $\wedge$ (1974) Phys Stat Sol 81:9-47

15. Müller U, Ammann M, Burlscher H, Schmidl-Ott $\wedge(1991)$ Pliys Rev I3 44:8284-8287

16. Krolikowski WF (1967) Ph D Thesis Stanford Electronics Laboratories

17. Lin SF, Spicer WL (1976) Phys Rev B 14:4551-45.58

18. Goldmann $\Lambda$, Tejeda J, Shevehik NJ, Cardona M (1974) Phys Rev B 10:4388-4402

19. D'lluysser $\Lambda$, Lerebours-Hannoyer B, L.englet M, Bonnelle JP'(1981) J Solid State Chem 39:246-256 